\title{
Knowledge, Attitude and Practice of the Parents Regarding Child Vaccinations in Arar, Northern Saudi Arabia
}

Ashwaq Arar S Alruwaili, Nagah Mohamed Abo El-fetoh', Thmer Arar S Alruwaili, Waad Alazri S Alanazi, Hala Hamdan R Alhazmi, Noor Awad B Alanazi,Hibah Abtan B Alshammari, Arwa Ahmed A Alshammari, Ahlam Hussein Alrwaili

Faculty of Medicine, Northern Border University, Arar, KSA, 2. Department of Community Medicine, Faculty of Medicine, Sohag University, Sohag, Egypt

\begin{abstract}
Background: Parental decisions regarding vaccination are very vital for increasing the vaccination rate and parent compliance to the immunization schedule. Worldwide studies show that besides other factors, parental knowledge and beliefs have major influence on starting and continuing of child vaccination. Objective: The study aim to assess knowledge, attitude and practice of the parents regarding child vaccinations in Arar, Northern Saudi Arabia. Methods: A cross-sectional community based study carried out during the period from 1st January to 30th July 2018. A systematic random sampling technique was used; 367 participants was included. Data collected using a pre-designed online questionnaire distributed among parents of children and adolescents to be self-administered. Results: the majority (40.1\%) of children aged less than 6 years old, $58.9 \%$ were males, fathers' education was university or more in $47.7 \%$ of participants and mothers' education was secondary school $75.5 \%$. Most $(88.3 \%)$ of parents were sure that the vaccinations are important for their children, $68.4 \%$ think vaccination reduces the probability of death or illness of a child, $85.6 \%$ think that vaccinations reduces the number of infectious diseases, $89.6 \%$ think that the vaccinations have a role in the child health, $6.8 \%$ were aware that some vaccinations are accompanied with side effects such as fever and $83.1 \%$ were aware that even healthy child needs vaccination. $70.1 \%$ of parents gave their child all mandatory vaccines, $77.9 \%$ follow the child's compulsory immunization, $76.6 \%$ of parents feel secure after vaccination of their children. Conclusion: knowledge and acceptance of childhood vaccinations, perceptions of vaccinerelated health benefits is good among parents in Arar, Northern Saudi Arabia.
\end{abstract}

Keywords: children; cross sectional; immunization; parents; Arar, Northern Saudi Arabia; vaccine

\section{INTRODUCTION}

Immunization is the most cost-effective and the highest impact health intervention which reduces hospitalization, treatment expenditure, and mortality ${ }^{[1]}$. There are many barriers against immunization, including misinformation about vaccines, adverse effects of vaccines, vaccinepreventable diseases, and disease development after the administration of vaccines ${ }^{[2]}$. Although in the past few decades; developed countries have seen sufficient improvement in vaccination coverage, low rates of complete vaccination still pose a problem in the developing countries. Surveys have shown that almost one third of the deaths among the children under the age of five can be prevented by vaccine ${ }^{[3]}$.

Parents' decisions regarding immunization are very important for increasing the immunization rate and compliance and for decreasing any possible immunization errors. Parents' knowledge and practices regarding immunization are the major factors that contribute to their vaccination decisions ${ }^{[4]}$. Studies have shown that improving parents' knowledge regarding vaccines improves immunization status and affects the success of immunization programs ${ }^{[5]}$. This is because parents are the primary health decision-makers for their children, their knowledge and practices regarding immunization in general have a great impact on the immunization status of their children ${ }^{[6,7]}$.

To improve parents' awareness, good knowledge regarding vaccination is required. Therefore, physicians, pharmacists, nurses, and others health care providers should provide parents with correct information about the risks and benefits of vaccines ${ }^{[8]}$. The most important factor affecting parental practice is communication between parents and the sources of information or immunization providers. Improving communication will improve parents' perceptions of the benefits and risks of vaccines ${ }^{[9,10]}$.

The aim of this study was to assess knowledge, attitude and practice of the parents regarding child vaccinations.

\section{METHODS}

A cross-sectional community based study conducted in Arar, Northern Saudi Arabia. The study included 367 participants. The study period was from $1^{\text {st }}$ January to $30^{\text {th }}$ July 2018. A systematic random sampling technique was used; we included parents of every $10^{\text {th }}$ family. Data collection: using pre-designed online questionnaire distributed among parents of children and 
adolescents to be self-administered. The questionnaire had brief introduction or explanation of the idea of the research to children parents. Parents filled out the predesigned questionnaire to collect data including: Socio-demographic characteristics of the participants including age, sex and educational status. If the parents had knowledge about vaccination importance. If the child completed the immunization schedule or not

Statistical analysis: Collected data was coded and analyzed using statistical package for the social sciences (SPSS, version 15). Descriptive statistics for the prevalence and quantitative variables were used. Relation between knowledge of parents and competence of immunization schedule for children was determined using A 2sided, $\mathrm{p}$-value of less than 0.05 was considered statistically significant.

Ethical considerations: This study was reviewed and approved by the Research Ethics Committee of Faculty of Medicine, Northern Border University. Participants were informed that participation is completely voluntary and data collectors introduced and explained the research to participants. No names were recorded on the questionnaires and all questionnaires were kept safe.

\section{RESULTS}

Most children (40.1\%) aged less than 6 years old, $58.9 \%$ were males, fathers' education was university or more in $47.7 \%$ of participants and mothers' education was secondary school in $75.5 \%$.

Table 2 reports knowledge of the parents about child's vaccinations. $88.3 \%$ of parents were sure that the vaccinations are important for their child, $68.4 \%$ think vaccination reduces the probability of death or illness of a child, $85.6 \%$ think that vaccinations reduces the number of infectious diseases, $89.6 \%$ think that the vaccinations have a role in the child health, only $68.1 \%$ believe that vaccinations have certain age, $66.2 \%$ were aware that there are many types of vaccines, $6.8 \%$ were aware that some vaccinations are accompanied with side effects such as fever and $83.1 \%$ were aware that even healthy child needs vaccination.

Table 3: Discuss the attitude of parents from child's vaccination. $70.1 \%$ of parents gave their child all mandatory vaccines, $77.9 \%$ follow the child's compulsory immunization, only $30 \%$ of parents were looking for additional immunizations for their child, $76.6 \%$ of parents feel secure after vaccination of their child, $83.9 \%$ of parents support the vaccination program in their country, $91 \%$ advice their relatives and friends to vaccinate their children, only $48 \%$ think that vaccination of child is very important, $50.1 \%$ important and $79.6 \%$ keen to complete all doses of vaccination when there is more than one dose. Regarding source of information; $41.1 \%$ have their information from relatives and friends, $36 \%$ from the doctors in the primary health care center, $19.6 \%$ from social media and $3.3 \%$ from T.V.

Table (1): Socio-demographic characters of the studied parents and children, Arar, 2018(N=367).

\begin{tabular}{|c|c|c|}
\hline Variables & Frequency & Percent \\
\hline \multicolumn{3}{|l|}{ Child age group } \\
\hline$<6$ & 147 & 40.1 \\
\hline $6-$ & 92 & 25.1 \\
\hline $12-$ & 40 & 10.9 \\
\hline $18-$ & 51 & 13.9 \\
\hline $24+$ & 37 & 10.1 \\
\hline \multicolumn{3}{|l|}{ Sex } \\
\hline Female & 151 & 41.1 \\
\hline Male & 216 & 58.9 \\
\hline \multicolumn{3}{|l|}{ Fathers' education } \\
\hline Secondary & 173 & 47.1 \\
\hline University or more & 175 & 47.7 \\
\hline Preparatory & 17 & 4.6 \\
\hline Primary & 1 & .3 \\
\hline Illiterate & 1 & .3 \\
\hline \multicolumn{3}{|l|}{ Mothers' education } \\
\hline Illiterate & 18 & 4.9 \\
\hline Primary & 63 & 17.2 \\
\hline Secondary & 277 & 75.5 \\
\hline University or more & 9 & 2.5 \\
\hline \multicolumn{3}{|l|}{ No. of children } \\
\hline 1 & 105 & 28.6 \\
\hline 2 & 75 & 20.4 \\
\hline 3 & 56 & 15.3 \\
\hline 4 & 56 & 15.3 \\
\hline 5 & 48 & 13.1 \\
\hline $6+$ & 27 & 7.3 \\
\hline \multicolumn{3}{|l|}{ Fathers' age group } \\
\hline $20-30$ & 139 & 37.9 \\
\hline $31-40$ & 165 & 45.0 \\
\hline $41+$ & 63 & 17.2 \\
\hline \multicolumn{3}{|l|}{ Mothers' age } \\
\hline$<20$ & 13 & 3.5 \\
\hline
\end{tabular}




\begin{tabular}{|l|c|c|}
\hline $20-30$ & 214 & 58.3 \\
\hline $31-40$ & 119 & 32.4 \\
\hline $41+$ & 21 & 5.7 \\
\hline
\end{tabular}

Table (2): Knowledge of the parents about Childs' vaccinations $(\mathrm{N}=367)$.

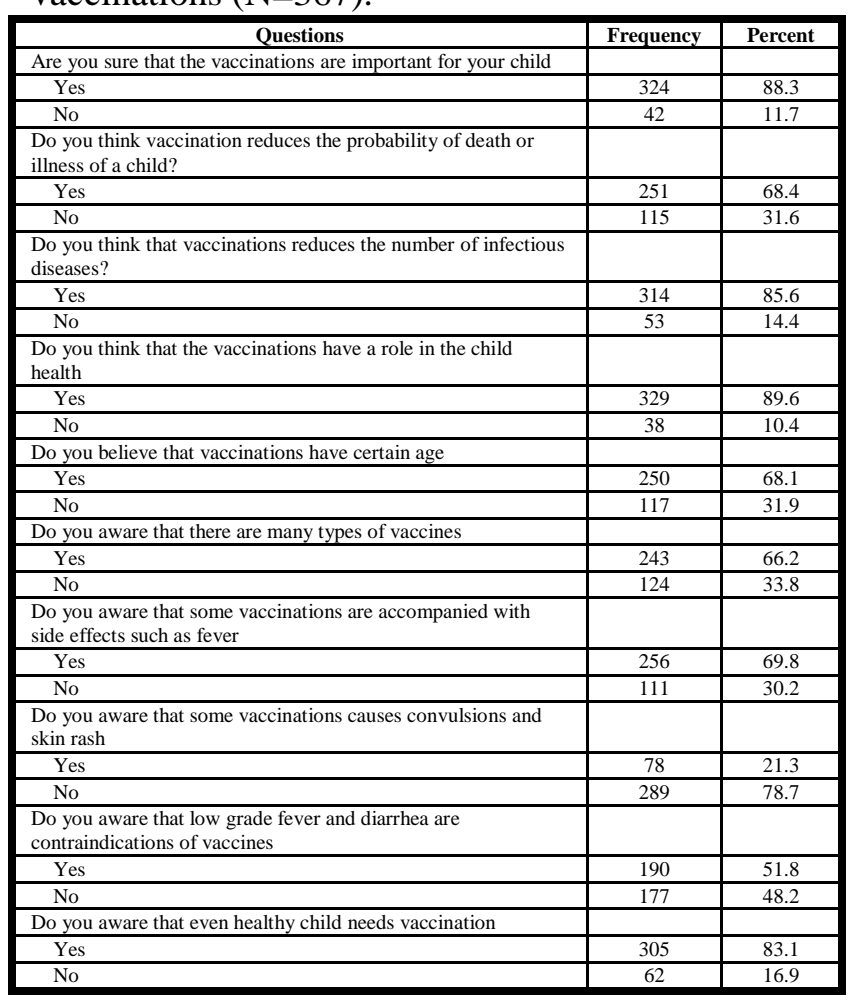

Table (3): Attitude of the parents from the child vaccinations $(\mathrm{N}=367)$

\begin{tabular}{|l|c|c|}
\hline \multicolumn{1}{|c|}{ Questions } & Frequency & Percent \\
\hline Did you give your child all mandatory vaccines? & & \\
\hline Yes & 261 & 71.1 \\
\hline No & 106 & 28.9 \\
\hline Do you follow the child's compulsory immunization? & & \\
\hline Yes & 286 & 77.9 \\
\hline No & 81 & 22.1 \\
\hline Are you looking for additional immunizations for your child? & & \\
\hline Yes & 110 & 30.0 \\
\hline No & 257 & 70.0 \\
\hline What do you feel after vaccination of your child? & & \\
\hline Security & 281 & 76.6 \\
\hline Fear & 86 & 23.4 \\
\hline Do you support the vaccination program in your country & & \\
\hline Yes & 308 & 83.9 \\
\hline No & 59 & 16.1 \\
\hline $\begin{array}{l}\text { Do you advice your relatives and friends to vaccinate their } \\
\text { children }\end{array}$ & & \\
\hline Yes & 334 & 91.0 \\
\hline No & 33 & 9.0 \\
\hline $\begin{array}{l}\text { Do you belief that the vaccination program started from the } \\
\text { first week of life? }\end{array}$ & & \\
\hline Yes & 299 & 81.5 \\
\hline No & 68 & 18.5 \\
\hline What is your assessment of the child vaccinations? & & \\
\hline Not important & 7 & 1.9 \\
\hline Important & 184 & 50.1 \\
\hline Very important & 176 & 48.0 \\
\hline $\begin{array}{l}\text { Are you keen to complete all doses of vaccination when there } \\
\text { is more than one dose }\end{array}$ & & \\
\hline Yes & 292 & 79.6 \\
\hline No & 75 & 20.4 \\
\hline
\end{tabular}

\begin{tabular}{|l|c|c|}
\hline Did you read about vaccinations before? & & \\
\hline Yes & 166 & 45.2 \\
\hline No & 201 & 54.8 \\
\hline What is your Information source about vaccinations? & & \\
\hline The doctors in the primary health care center & 132 & 36.0 \\
\hline Relatives and friends & 151 & 41.1 \\
\hline The T.V & 12 & 3.3 \\
\hline The social media & 72 & 19.6 \\
\hline
\end{tabular}

\section{DISCUSSION}

Immunization is the process whereby a person is made immune or resistant to an infectious disease, typically by the administration of a vaccine. Vaccines stimulate the body's own immune system to protect the person against subsequent infection or disease. Immunization is a proven tool for controlling and eliminating life threatening infectious diseases and is estimated by WHO to avert between 2 and 3 million deaths each year ${ }^{[11]}$. Parental decisions regarding vaccination are very vital for increasing the vaccination rate and parent compliance to the immunization schedule. Worldwide studies show that besides other factors, parental knowledge and beliefs have major influence on starting and continuing of child vaccination ${ }^{[12]}$. This is across sectional study conducted among 367 of the studied parents and children, Arar, KSA .The study aimed to assess knowledge, attitude and practice of the parents regarding child vaccinations.

As regards knowledge of the parents about Childs' vaccinations our study reported; $88.3 \%$ of parents make sure that the vaccinations are important for their child, $68.4 \%$ think that vaccination reduces the probability of death or illness of a child, $85.6 \%$ think that vaccinations reduces the number of infectious diseases, $89.6 \%$ think that the vaccinations have a role in the child health, $83.1 \%$ aware that even healthy child needs vaccination, $66.2 \%$ know that there are many types of vaccines , $69.8 \%$ agreed that some vaccinations are accompanied with side effects such as fever and only $21.3 \%$ aware that some vaccinations causes convulsions and skin rash. In Taif, Saudi Arabia across sectional study conducted among 731 parents reported, the majority of parents $672(91.9 \%)$ knew the role of routine vaccination in protecting children from some infectious diseases and its complications, (86.9\%) parents knew the timing of the first dose in vaccination schedule, $(41.6 \%)$ knew that administration of multiple doses of the same vaccine is important for child immunity ${ }^{[13]}$. An observational, cross sectional study was conducted in AlMadinah, Saudi Arabia among 614 participants, 
the majority were mothers (86\%), (77.9\%) of participants agreed that vaccination is generally not harmful for children, $40.2 \%$ said that routine vaccination protect children against infectious diseases and their complications and it is necessary to vaccinate children during vaccination campaigns such as polio campaigns $(74.8 \%)^{[15]}$. A cross sectional survey study that was carried out among 600 different Saudi parents form different parts of Jeddah City, most of the parents rated that vaccination could prevent infectious disease $(79.7 \%)$, decrease the mortality rates $(76 \%)$, maintain child health $(87.2 \%)$, $89 \%$ of the parents knew that some vaccines are associated with pain and fever while only $55.5 \%$ declared that vaccination is not supposed to cause convulsions and skin rashes and almost $96.3 \%$ of subjects supposed that even healthy child need vaccination ${ }^{[16]}$. In Riyadh, another study carried out among parents of 390 children reported, the majority of parents recognized correctly that vaccination prevents diseases $(82.6 \%)$, that there are different types of vaccines $(87.4 \%)$, vaccination enhances immunity $(89.2 \%)$ and healthy child need vaccination $(85.9 \%)^{[18]}$. Another study conducted among 2743 reported two-thirds of respondents $(66.7 \%)$ agreed that vaccines for children's immunization are safe; $80.7 \%$ stated that vaccination is more beneficial than harmful, only $16.9 \%$ of parents indicated that vaccines cause adverse events more frequently than other medical treatment, $62.7 \%$ that vaccines are amongst the most effective and least costly forms of medical treatment, and $35.9 \%$ that vaccines always warrant protection ${ }^{[14]}$. A prospective cross-sectional study was carried out on 110 parents residing in rural areas of Bangalore to assess level of knowledge about child vaccination amongst the parents showed that a majority of them $(72.2 \%$, ) had good knowledge score followed by average $(21.8 \%)$ and poor $(2.7 \%)$ [17]. In the United Arab Emirates a study conducted among 218 mother showed that more than $85 \%$ of the participants knew that childhood vaccinations prevent life-threatening diseases and $62 \%$ were aware that immunizations provide lifelong protection ${ }^{[8]}$.According to Attitude of the parents from the child vaccinations our study found that $71.1 \%$ of parents give their child all mandatory vaccines, $77.9 \%$ follow the child's compulsory immunization, $48 \%$ of parents said that vaccination is very important, $50.1 \%$ said it is important and $91 \%$ advised their relatives and friends to vaccinate their children. In Taif another study reported, the majority $(98.4 \%)$ of the parents either strongly agreed or agreed that child immunization is important, $91.5 \%$ of them considered immunization is more beneficial than harmful and $73 \%$ strongly agreed or agreed that vaccines are safe [13]. Another study reported, majority of the parents $(88.4 \%)$ agreed that vaccinations are important to keep child's health, compliance with the $\mathrm{MOH}$ vaccination schedule is very important $(85.7 \%)$ and benefits of vaccinations exceeds their harms $(81.4 \%)$ and only $43 \%$ of them disagreed that vaccine doesn't give child immunity against infectious diseases and he may get infection even after vaccination ${ }^{[15]}$. In Jeddah another study found that the parent's attitude toward vaccination was positive among most of them as all of them declared that the vaccination is beneficial and will advise relatives to immunize their children. Also, $83.5 \%$ felt that vaccination is safe and $89.3 \%$ are in favor of obligatory vaccination ${ }^{[16]}$.In our study $36 \%$ of parents know about vaccination from the doctors, $41.1 \%$ from relatives and friends, $19.6 \%$ from social media and only $3.3 \%$ from the T.V. Another study found that; the main sources of information on vaccination are medical institutions $(92.2 \%)$, print media $(38.1 \%)$, and broadcast media (38.2\%) ${ }^{[14]}$. Another study reported that most of parents $(58.1 \%)$ had their information regarding child vaccination from medical staff, followed by social media $(17.4 \%)$ and books (14\%) ${ }^{[15]}$.In Riyadh, a study showed that physicians were the main source of information $(77.7 \%)$ for the parents about immunization, followed by TV (37.6\%), Internet $(21.7 \%)$ and newspapers $(13.3 \%)^{[18]}$.

\section{CONCLUSION AND RECOMMENDATIONS}

Knowledge and acceptance of childhood vaccinations, perceptions of vaccine-related health benefits is good among parents in Arar, Northern Saudi Arabia. But we recommend more awareness campaigns to increase the knowledge and improve the attitude and practice to reach the hundred percent to keep the good health of those vulnerable group.

\section{REFERENCES}

1. Caingles SE, Lobo JJ (2011): Survey on the knowledge, attitude sand practices of parents in Barangay 8a, District 1, Davaocity regarding their children's immunization. PIDSP J., 12(1):46-53.

2. Ritvo $\mathbf{P}$, Irvine $\mathrm{J}$, Klar $\mathrm{N}$ et al. (2003): A Canadian national survey of attitudes and knowledge regarding preventive vaccines. J Immune Based Ther Vaccin, 1(1):3. 
3. Introduction U NICEF (2015): Available from: http://www.unicef.org/ immunization/ index_2819.html

4. Gellin B, Maibach E, Marcuse E (2000): Do parents understand immunizations? A national telephone survey. Pediatrics,106(5):10971102.

5. Anjum Q, Omair A, Inam $S$ et al. (2004): Improving vaccination status of children under five through health education. J Pak Med Assoc., 54(12):610.

6. Szilagyi $\mathrm{P}$, Hager $\mathrm{J}$, Roghmann $\mathrm{K}$ et al. (1994): Immunization practices of pediatricians and family physicians in the United States. Pediatrics, 94(4):517-523.

7. Orenstein WA, Atkinson W, Mason D et al. (1990): Barriers to vaccinating preschool children. J Health Care Poor Underserved, 1(3):315-330.

8. Bernsen R, Al-Zahmi F, Al-Ali A et al. (2011): Knowledge, attitude and practice towards immunizations among mothers in a traditional city in the United Arab Emirates. J Med Sci., 4(3):114-121.

9. Hall J, Roter D, Katz N (1988): Metaanalysis of correlates of provider behavior in medical encounters. Med Care, 26(7):657-675.

10. AlLela $O$ (2012): Influence of health providers on pediatrics' immunization rate. $\mathrm{J}$ Trop Pediatr.,58(6):441-445.

11. Global Immunization Vision and Strategy (2015): WHO/UNICEF. Geneva.

12. Hamid S, Andrabi SAH, Fazli A, Jabeen R. Immunization of Children in a Rural Area of North Kashmir, India: A KAP Study. Online J Health Allied Scs., 11(1):10.
13. Yousif M, Albarraq A, Abdallah $M$ et al. (2015): Parents' Knowledge and Attitudes on Childhood Immunization, Taif, Saudi Arabia. J Vaccines Vaccin., 5:215.

14. Zagminas K, Surkiene G, Urbanovic $\mathbf{N}$ et al. (2011): Parental attitudes towards children's vaccination. Medicina (Kaunas), 43(2):161-9.

15. Alharbi K, Alfahl S (2017): Parents' Knowledge, Attitude and Practice towards Childhood Vaccination, AlMadinah, Saudi Arabia 2017. Neonat Pediatr Med., 3: 126.

16. Ahmed Alenazi A, Alshareef $R$, Alabudib $F$ et al. (2017): Assessment of Knowledge and Attitude and Practice of Parents about Immunization in Jeddah City, 2017.The Egyptian Journal of Hospital Medicine, 69 (7): 2939-2943.

17. Nosenoor M (2017): Assessment of Parents' Knowledge, Attitude and Practice about Child Vaccination in Rural areas. Journal of Pharmaceutical Research, 16: 229-236.

18. Al-zahrani J (2013): Knowledge, attitude and practice of parents towards childhood vaccination; majmaah j. Health sciences, 1(1):29-38. 